\section{Towards One System?}

The European Research Area Initiative, the Integration of Research Systems and the Changing Leeway of National Policies ${ }^{1}$

\section{by Jakob Edler, Fraunhofer Institute for} Systems and Innovation Research, ISI, and Stefan Kuhlmann, ISI, and Copernicus Institute for Sustainable Development and Innovation, Utrecht University

This article speculates about the integration of European research systems triggered by the ERA initiative of the European Commission. Its main argument is that integration of research systems in Europe is driven by political, economic, social dynamics at various levels and takes place within and outside this formal system of the EU. These complex developments are interdependent. There are strong hints that individual actors and stakeholder groups shift their attitudes and their reference level of expectation, adjust their definition of interest and their behaviour according to the new opportunities defined at the new - the European level. As in this double dynamic the oligopolistic, inter-national power structures soften and increasingly develop into a more complex web of governance structures, the role of national policy-makers changes. How they define their new role will depend on their ability and openness to actively shape the integration process.

\section{Introduction}

In January 2000, the Commission challenged the current division of labour in research and innovation policy-making with its now famous document "Towards a European Research Area (ERA)" (European Commission 2000a). This paper contained the first sweeping reform attempt in European research policy-making in the last 20 years $^{2}$ and took the research community in Europe totally by surprise (Kuhlmann, Edler 2003). With this new approach, the Commission claimed to overcome the existing multi-layer architecture of European research and policy-making with three distinct research and technology policies on each governance level, with - for most EU countries at least - a minor and complementary role of
Europe as compared to the national level. Among many other things, it attempts to build up a European research identity and enable more effective and strategically planned panEuropean cooperation. Meanwhile ERA has even found its way into the final draft of the European Constitution, which states that the Union shall achieve a European Research Area in which researchers, scientific knowledge and technology flows freely...” (Article III-146).

But also outside of the institutionalised system of Europe, directly or indirectly, ERA has been stimulating a still increasing number of 'bottom-up' trans-border initiatives between research organisations and research funders for collaborative research and/or funding. For example, there is now a serious debate and a growing will of relevant institutional actors on national and trans-national levels to create a pan-European funding agency for basic research ("European Research Council") - a quite unrealistic aim until the late 1990s. This reflects a strong, ongoing internationalisation trend in industrial and public research (Edler 2004). Scientists collaborate much more across-borders. Interestingly, as Frietsch has shown recently for German scientists, the growth rate of this cooperation has been stronger with European partners than with nonEuropean partners (Frietsch 2004).

Against this background, the paper raises three questions:

- Is there empirical evidence or at least some significance of an increasing integration of research systems and their governance in Europe?

- Which role do national policy actors play in the process of Europeanisation? Are national governments, research councils and relevant public research organisations shaping, supporting, by-passing, blocking or ignoring ERA-related initiatives?

- Do ERA-policies minimise, change or increase national policymaker's leeway? Can we observe emerging new "spaces" for policymaking across levels and actors in Europe? Are there novel policy-mixes? Is there a new governance pattern dawning?

Thorough answers to such questions would require carefully conceptualised comparative research, both with an in-depth and a long-term 
ex post scope - i.e. a resource-intensive and lengthy enterprise. The authors of this paper did not dispose of such resources nor did they intend to wait until the present, dynamic development of the European research system has become history: Instead, the paper ventures to speculate about intermediate results, based on informed observation, limited empirical study, and involvement in related strategic intelligence and policy consultancy.

In the following (section 2) we will explain our approach towards the concept of integration and put forward our main argument. Then (section 3) we will discuss the implications of the ERA initiative for research integration inside the European institutional system. In section 4 we look at developments beyond the EU political system, and the repercussions of these developments on the formal integration process. In both dimensions we will shed albeit still dim - light on the role national governments are playing in these developments. Finally, we will (section 5) summarize our findings and draw some conclusions.

\section{Integration and the role of national gov- ernments}

Meaningful statements about the level, dynamics and direction of integration and the role of national governments require a conceptualisation of "integration". Our unit of analysis are research systems in Europe and their governance. Research systems, in our perspective, are embedded in innovation systems (IS; see e.g. Edquist 2004): The heuristic notion of IS tries to cover the "biotope" of all those institutions which are engaged in scientific research, the accumulation and diffusion of knowledge, which educate and train the working population, develop technology, produce innovative products and processes, and distribute them; to this belong the relevant regulative bodies, as well as the state investments in appropriate infrastructures. IS extend over schools, universities, research institutions, industrial enterprises, the politico-administrative and intermediary authorities as well as the formal and informal networks of the actors of these institutions. Each system is different; sustainable systems develop their special competitive scientific, educational, technological profiles and strengths only slowly, in the course of decades, or even centuries. National and regional IS compete and co-evolve, and it is an open question whether they might "integrate", in particular in the context of Europeanisation (Kuhlmann 2001; Borras 2004).

Against this background we need to look at the political governance of research as well as at the interactions and behavioural schemes of research organisations, intermediate bodies and individual researchers. Our major premise is that integration of research systems and their governance is a political, an economic and a social process. In order to understand integration of research systems we need to shed light both on the political elites codifying this integration and the economic and social actors driving interaction further and further.

To do so, we follow a definition of integration by William Wallace, according to which integration is

"the creation and maintenance of intense and diversified patterns of interaction among previously autonomous units.” (Wallace 1990, 9)

This definition has the benefit of covering political and non-political actors ("units”). It also highlights not only the growing intensity of interaction, but also the diversity of these interactions and their regulatory context, as Wallace himself differentiates formal and informal integration:
Informal integration "consists of patterns of interactions which develop without the impe- tus of deliberate political decisions, following the dynamics of markets, technology, com- munications networks and social change”.
Formal integration consists of "changes in the framework of rules and regulations" impinging upon the informal flows and in- teractions.

Thus, the main argument of this article is that integration of research systems in Europe happens within the formal system of the EU, i.e. it is triggered by EU decisions and frameworks, and outside this formal system. Integration is thus driven by political, economic, social dynamics at various levels. These complex developments are interdependent and exert influence on each other. We see strong hints that individual actors and stakeholder groups shift their attitudes and their reference level of expectation, adjust their definition of interest and their 
behaviour according to the new opportunities defined at the new - the European - level (see also Hurwitz 1980, Frei 1985, Giering 1997).

In addition, we argue that the role of national governments changes in the context of this double dynamic. To be sure, they still set the authoritative decisions shaping the EU system. But we follow Stone Sweet and Sandholtz and argue that the

"expansion of trans-national society, the pro-active activities of a supranational organisation, and the growing density of transactions and rules...gradually, but inevitably, reduce the capacity of the member states to control outcomes" (Stone Sweet, Sandholtz 1997, p. 299-300).

\section{Integration within the EU system: the meaning of ERA}

The rationale underlying the ERA approach was that Europe needs to exploit the potential of its knowledge societies and economies much more effectively. The ongoing and accelerating process of European economic integration, in combination with the opportunities opened up by the enlargement of the European Union, and the growing challenges of economic and technological globalisation, therefore, functionally lead to an integrated research and innovation policy approach in Europe. Ideally, this would optimise the usage and development of critical research and innovation infrastructures in Europe, thereby exploiting the full potential of an integrated Europe. Such a development would certainly mean a quantum leap in European governance of research, technology and innovation.

There are three features of ERA that potentially act as catalysts of integration of the European Research system:

- The New Instruments to implement the Framework Programme and to boost integration of research actors,

- The discursive apparatus set up by the Commission in form of the Open Method of Coordination to accompany the implementation of ERA via inter-governmental reflexive activities,

- The ERA-NET activities as an attempt to accompany the research integration with an administrative integration.
All of these integration instruments address different stakeholders. While the New Instruments target the traditional addressees of funding programmes, the Open Method of Coordination aims at a deeper integration of national research ministries, complemented by ERANET as an integration means of funding and management bodies, including officials from research ministries on the level of individual programmes. Thus, in principle the whole range of research (policy) actors within the EU system is addressed. Has the ERA-Initiative been a Catalyst for a European research system?

\section{The New Instruments and the integration of research via the $E U$}

The aim of the New Instruments that have been implemented with the $6^{\text {th }}$ Framework Programme (2003-2007) is to establish selforganised, longer-term cooperation across Europe that would replace the existing approach of short-term, small-scale, centrally managed research projects. This would give the supranational body European Commission more autonomy to initiate projects and programmes that directly affect national research actors and, in addition, would take coordination of national policies more seriously.

The qualitative leap forward is signified both by the size and - more importantly - the change in governance within these New Instruments. First of all, the framework of cooperation has been expanded. With the New instruments the Commission grants large scale projects. The size of projects in the first call within the Framework Programme 6 is remarkable. On average, the New Instruments comprise 32 participants, while across all instruments (including the new ones) the average is only 17. Almost 6000 participants in the Integrated Projects and almost 3000 participants in the Networks of Excellence demonstrate the weight of the New Instruments within the activities funded in the Framework programme (Marimon 2004, own calculations). Far more than $50 \%$ of the funds within the first call have been allocated to the New Instruments (Marimon et. al. 2004, Annex). Thus, the logic of small scale projects has been complemented by larger trans-national structures. 
However, it is not so much the sheer size of projects, but - second - the governance schemes that seem to emerge within these new structures that would mean a leap forward in European RTD policy-making. For the first time research organisations and private companies are entitled to organise the final distribution of the budget they are allocated as a trans-national network they have applied for and set in motion. Networks of excellence, for example, have set up governance mechanisms such as formal calls for proposals, peer review procedures and other quality checks, democratic decision-making mechanisms and delegations of power, internal communication infrastructures and external dissemination channels. The basic allocation decision is still taken by the Commission, which has also kept the obligation to check that the distribution and usage of budgets is in line with what the networks have pledged in their proposals. Moreover, national governments still have the final say in the allocation decision through the various inter-governmental programme committees. But yet: The networks' new selfgovernance prevails, their work follows the principle of sound science, and they are largely independent, for the first time in the history of European integration in research policy-making.

The opportunities offered by the New Instruments have prompted early reactions by large research organisations in Europe. Organisations, such as Fraunhofer Society and MaxPlanck-Society in Germany, anticipated the possibilities offered by the New Instruments. They intensified their activities in Brussels, communicated intensively with the Commission, mobilised their institutes and co-ordinated their activities with other large scale organisations. The coordinative activity within the New Instruments and the strategic backing this has by the national headquarters signifies a next step of strategic integration independent from the national ministries or funding structures.

The role of and consequences for national governments with regard to the set up and implementation of the New Instruments is somewhat ambiguous. All heads of state have agreed, and in principle there is a consensus on the logic of bottom up self governed networks between national research administrations across Europe. However, the latter have not been part of the genesis of the New Instruments and not been involved in the design of instruments. This has caused severe irritations especially with ministries of smaller Member States. The nice and easily comprehensible system of small scale projects, whereby the logic of mathematics has it that small countries benefit more than big ones, has been shaken. Small countries have after the principle Council decision - openly issued criticism on the consequences of the New Instruments for their systems.

\section{The Open Method of Coordination: a push towards an integrated space of reflexivity?}

The Commission has set up a reflexive discourse with the national governments in order to measure progress in the research efforts in Europe (Caracostas 2003; Kaiser, Prange 2003). This discourse is part of the Open Method of Coordination (OMC) that was introduced to all kinds of policies within the EU, especially in areas where "national diversities and regional particularities have to be taken into account carefully" (Presidency Conclusion 2000). Thus for the OMC in research policy the starting point was the diversity in science and research systems across Europe. The obvious purpose of the first OMC activities was the benchmarking of this diversity along five dimensions $^{3}$ in order to improve the understanding of national potentials and bottlenecks and consequently - better tailor Community efforts to the real needs of national research systems.

Subsequently, five working groups of high level representatives of national Ministries responsible for research have been set up. Interestingly, the scope of their work was not confined to the exchange and dissemination of indicators, but rather they discussed "best practice” as regards policy-instruments and policymixes and even institutional set-ups of research and the very objective of research policies (quoted in Caracostas 2003, p. 52). The definition and exchanges of benchmark indicator and policy practice has been understood as the creation of a common basis upon which better coordination of national and regional policies may occur in the future. Even more, the OMC should fix "guidelines for the Union" in the area of research and "translate these European guidelines into national and regional policies by setting specific targets and adopting meas- 
ures, taking into account national and regional differences" (CREST 2004, p. 7). Thus, CREST, the intergovernmental body within the EU advising the Commission, has agreed to the normative dimension of the OMC impinging upon their own national and even regional policies. For the time being the OMC means integration of methodological approaches, discursive practices and normative orientations in policymaking administrations rather than integration of policy-making itself.

There is a potential that this discursive integration leads towards a truly European space of reflexivity. The OMC activities are accompanied by further European measures to report on policy practices and outcomes. DG Enterprise has long set up a framework for innovation policy with a so-called trend chart $^{4}$ and the scoreboard ${ }^{5}$, increasing transparency and enabling permanent benchmarking between countries. Recently, DG Research, together with its research centre Institute for Prospective Technological Studies (IPTS) in Seville, has launched a similar activity to trend chart in the area of research policy-making called "ERAWATCH”. A prototype study has been completed, and a new pan-European network will be set up early in 2005. This will broaden the institutionalisation of European reference systems and their underlying networking. National policy-makers, albeit sceptical as regards the multiple efforts at the European level and the danger of inefficiencies, have started to understand the merits of such an integrated European system of reflexivity. They have, in principle, backed the ERAWATCH approach in an advisory body. More generally, they demand a stronger linkage of OMC work to the existing reference systems in Europe, and even beyond (OECD) (CREST 2004, p. 10). Moreover, the ERAWATCH proto-type has shown that such a reference system is welcomed by almost all of the potential users at national level, i.e. funding agencies, business federations, large research organisations and even representatives of subnational entities (Cunningham et. al. 2004).

What does the OMC and related reflexive activities mean for the leeway of national policy-makers. First of all, while at the level of high politics back in Lisbon national governments have agreed to cooperate within the OMC, national policy-makers at the working level have been somewhat reluctant. They have repeatedly complained about the burden this kind of reporting and discourse at European level puts at them. ${ }^{6}$ This is not so much due to the work load attached with increased discourse and reporting, but due to the apparent necessity to align to intellectual, methodological and conceptual approaches defined by the Commission or by various groups of Member states. The OMC has thus somewhat limited the room of manoeuvre of national policymakers. They are now obliged to use the same language, to tell similar stories, to use the same benchmarking indicators and to legitimise their national policies at home and in Brussels vis-àvis the European goals. National and regional policy-makers are increasingly aware that the European discourse exerts not only a rhetoric but also a normative pressure on them. Especially smaller countries feel that they cannot influence the discourse but have to adapt to it.

However, the Lisbon/Barcelona process and the underlying discourse supporting it have at the same time provided an opportunity for national policy makers. Some ministries have succeeded in using the normative link to the $3 \%$ goal and the analytical findings at European level to boost their national R\&D policies, as the ERA initiative has highlighted the meaning of $\mathrm{R} \& \mathrm{D}$ for competitiveness and - via the OMC - has started a highly visible performance competition. This is true both for older Member States and new ones (Edler, Havas 2004).

\section{ERA-NET: Integration of research policy from below}

A third pillar of the ERA process is the increased cooperation of research administrations and funding bodies. With the so-called ERANET projects these national or regional institutions may work towards a co-ordination and networking of their programmes. $90 \%$ of all proposals that are funded implement "joint activities" and "trans-national research activities” (ibid.). ERA-NET is strictly bottom up and thus does not focus on selected issue areas. In the vision of the Commission this kind of preparatory work will lead to a mutual opening up of programmes and, at a later stage, the definition of joint programmes. The networks should increase the "reflection on intensified 
trans-national co-operation" and should be durable enough to make a change (up to five years), exerting a "lasting structuring and strengthening effect" (EU-Commission 2004a, p 7). With a dedicated budget of $€ 150$ Million the Commission funds the costs of co-ordinating the exchange and common work by the administrations.

The ERA-NET scheme has been widely embraced. By November 2004, 32 ERA-NET projects are operative and 23 preparatory activities are running that will turn into ERANET projects. Interestingly, Germany has played a major role in the ERA-NET activities. 53 German institutions have participated in 29 out of the 32 projects funded up until March 2004, 12 of which have coordinated their networks. Out of the 53 participations, 22 partners have been from Ministries.

Currently, the ERA-NET-Plus scheme is being discussed which would give co-operating bodies an incentive by providing a financial addon by the Commission to programmes implemented with joint calls. The idea behind this is an attempt by the Commission to build a bridge towards a full-fledged joint programming by national governments via the more flexible and modest ERA-NET-approach (Commission 2004b). Reactions of national administrations to that approach are mixed. ERA-NET certainly eases the attempts for mutual opening up of programmes. This had been started by the national ministries via CREST but only resulted in five minor attempts. Now, the national delegates to CREST have defined ERA-NET as major means to realise the opening up of national programmes in the future (ibid). At the same time ERA-NET-Plus would change the incentive structures of national administrations, including national programme managers in national ministries. The push towards integration of programmes could be even stronger with the carrot of additional funding, and flexible integration of programmes might finally start across Europe. For national policy-makers believing in the virtue of flexible integration this is a blessing, while for those national policy-makers eager to control for the benefits of their national programmes within national borders this is a curse. ERA-NET+ thus enlarges the leverage of national policy-makers, but only if international participation in their programmes is within their programme strategies. It is too early to judge the real integration effect at the programme level, but the range of participation and the overall positive judgement of national administrations suggest a high potential for deepening of the integration of research policies from below.

\section{Integration outside the institutional framework of the EU}

The second main strand of integration of research systems in Europe is evolving around the cooperation of researchers and of research organisations outside the EU institutional framework. We do not have the space in this paper to treat the institutional history of European research collaboration as regards e.g. the CERN (European Organisation for Nuclear Research), EMBO (European Molecular Biology Organisation), JET (Joint European Torus) etc. (e.g. Guzzetti 1995; Stein 2004) or the EUREKA initiative, borne mainly by multilateral inter-governmental agreements. Instead we will point to an increasing number of 'bottomup' trans-border collaborative initiatives between nationally based research organisations and research funders stimulated directly or indirectly by ERA, accelerating a process by which the national research organisations and their institutes grow out of their national boundaries in their strategic research activities.

\section{Integrative joint research funding}

At the European level, the European Science Foundation (ESF) - an association of 76 member organisations devoted to scientific research in 29 European countries, established in 1974 runs the EUROCORES programme, a research scheme combining national and European financial resources to support European scientists in addressing major research challenges. Furthermore, the European Heads of Research Councils (EUROHORCs) developed the European Young Investigators Awards (EURYI) Scheme in cooperation with the ESF. The aim of the scheme is to attract outstanding young researchers from anywhere in the world to work in Europe and lead their own research team. In an open competition funded by national research organisations in 16 European countries, EURYI provides resources to pursue an independent research ca- 
reer, including the development and building up of a research group.

Furthermore, there are many initiatives of various national institutions. Several of the major national public research organisations started to launch strategic cooperation agreements with relevant partner organisations in other European countries, e.g. Centre national de la recherche scientifique, France (CNRS)/ Fraunhofer-Gesellschaft (FhG); CNRS/MaxPlanck-Gesellschaft (MPG); Netherlands Organisation for Applied Scientific Research (TNO)/Joanneum Research. Such agreements aim at joint research strategies, the exchange of researchers, the establishment of joint centers, and last but not least at joint lobbying vis-à-vis public policy or industry. In addition, in 2005 the Nordic countries established the Nordic Research Board (NordForsk). NordForsk aims at a major role in realising the vision of the Nordic countries as a leading and integrated research region. NordForsk is an independent institution operating under the Nordic Council of Ministers for Education and Research. The institution is responsible for cooperation within research and research training. Finally, the French CNRS has initiated Laboratoires Européens Associés (LEA), as entities that associate research groups from two or three Western European countries. These laboratories and teams are working on a joint programme and share, for a period of four years (renewable) their resources ("laboratory without walls"). Their means (equipment, running costs, associate researchers positions) are provided by the CNRS and partner organisations or institutions, e.g. the German Max-Planck-Gesellschaft.

ERA also stimulated, directly or indirectly, the launching of cross-border funding streams from national sources. National research councils are opening-up their funding schemes for international participation, e.g. the Deutsche Forschungsgemeinschaft (DFG), funds international research cooperation in individual projects, coordinated programmes or projectpreparation measures.

In January 2005 the French President Jacques Chirac announced to create an agency for 'industrial innovation' to support technology and innovation projects in promising sectors. Government funding should concentrate in areas of technology where there are strong European companies, capable of bringing projects to commercial fruition; thereby the scheme would be open for international participation.

\section{Structural integration}

ERA also fostered, directly or indirectly, integration in structural terms: Relevant procedures and ways of organisation of research (funding) as well as institutional representation are becoming subject of mutual adaptation:

- Most recently, the ESF started to consider a merger with EUROHORCS. ${ }^{7}$

- In 2004 the EUROHORCs signed an agreement allowing a transfer of research grants if a researcher moves to a new position in one of the other participating countries. This principle has become known as "money follows researcher".

- The ESF has implemented a "Forward Looks' activity: The new instrument should enable Europe's scientific community to develop medium to long term views and analyses of future research developments in multi-disciplinary topics, and interact with policy makers. The aim is to bring together scientific foresight and national and European planning for research funding.

- The number and relevance of genuinely European professional organisations supporting knowledge generation is growing. Similarly, more and more national research (funding) organisations establish representations in Brussels; many of them collaborate in the IGLO network (Informal Group of Liaison Officers; for an overview Stein 2004); originally such offices were focused on EU research policies, meanwhile they deal far more generally with trans-border integration issues.

More generally, as a result of increased performance orientation within research institutions, but also as a reflection of the intellectual bias of (relatively) small national disciplinary communities the establishment of international quality benchmarks, the international exchange of referees, and the use of joint review panels have considerably grown - a trend that was certainly reinforced by ERA.

Finally, one can also observe an increasing awareness of the need for national policies 
improving the frame conditions of integration, such as the deregulation of inward/outward labour mobility or the creation of internationally compatible pension fund and health insurance systems.

\section{Development of a "European Research Council"}

The Commission's report on 'Europe and basic research' (2004c) highlights the "need to introduce a European level support mechanism for individual teams' research projects". The 2004 Spring Council, and later the informal Competition Council, welcomed this suggestion to create a mechanism to support basic research at European level. Following the reports of various groups and publications by a number of prominent individuals, there is now widespread consensus on the need for a European Research Council (ERC). The envisaged characteristics of an ERC are: an institutionally independent body; awarding funding through grants to proposals on a competitive basis; sole criterion of scientific excellence, appraised by independent peer review; grants to individuals or teams; in either established disciplines or multidisciplinary fields; no requirement for multi-nationality.

A potential longer term impact my be a new division of responsibilities and complementarities between ERC and national funding agencies: While an ERC would facilitate leading edge, risky, and novel type of research, irrespective of disciplinary and national borders, the national funders would concentrate on the enhancement of structural competencies within national, regional or sectoral research systems (support for young researchers and their career development; responsive mode funding across disciplines), thus enabling researchers to compete globally. An inevitable overlap of activities of the two levels would not necessarily be harmful.

Did the efforts towards an ERC have consequences for national policymakers and funders, so far? There is an increasing support by EUROHORCS; the hope for leverage effects: more money for research; higher quality standards; more professional selection procedures, more attractive European research system. Also, many governments are supportive, while some are still reluctant, and a few very negative.

\section{Summary and outlook: A new govern- ance pattern?}

The fabric of governance in European research is changing. The developments sketched above show that the integration of research systems in Europe and their governance is a complex process, unfolding at many levels in parallel, with feedback loops and complex interrelations. The role of national governments, the Commission or societal actors varies. The processes unfold with spill-over from one subarea to the other, driven by the Commission as supranational agent of integration and societal actors who have come to believe that the net benefit of an integrative step is positive.

Are there answers to our three guiding questions? In this paper we could only speculate, based on some non-systematic evidence:

- Is there increasing integration of research systems and their governance in Europe? Our short answer is: Yes. The integration processes observed, nevertheless, seem to unfold unevenly, spontaneously, and not necessarily in an effective manner - we see 1000 flowers blooming.

- Which role do national policy actors play in this game? Do they shape, support, by-pass, block or just ignore ERA-related dynamics? Our short answer is: A bit of all. As a general tendency one can state: The more competitive, professionally managed and internationally oriented an organisation is, the more prone it seems to cope with 'denationalisation' and integration, understanding this as a basis for increased own competitiveness.

- Did the leeway of national policymakers change? Are there emerging new "spaces" for policymaking across levels and actors in Europe, or novel policy-mixes? Are we witnessing the dawning of new governance patterns? Our short answer is: Yes. Again, we find 1000 flowers blooming. National "activists" aiming at the modernisation of research systems realise new normative arguments, borrowed from the European scale, providing them with leeway at home and helping them to influence discourse in Brussels. A strong wave of new bilateral or multilateral initiatives signifies an extended leeway alongside the EU. On the other 
hand, national "victims" of modernisation tend to blame Brussels for their reduced leeway and new normative pressure.

Hence, are we witnessing a shift of political power and governance in Europe's research systems? Our concluding speculation is: In Europe (also in US?) we observe a general move from oligopolistic (primarily national) power structures in research policy arenas to multiactor, multi-level arenas, characterised by a kind of network governance (Borras, Jacobsson 2004; Hartwig, Meyer 2002). In this context, large multinational companies as well as agile, flexible and internationally competitive "regional" entities (provided with sufficient autonomy, i.e. small countries; "Länder"; "Regions") are the winners of shifting governance. Within these complex dynamics, the EU Commission has lessons learned: The ERA initiative and its follow-up aim rather at intelligent mediation and stimulation than top-down central integration. Large member states' institutions (ministries etc.) will remain strong in financial terms, but are running the risk of suffering from institutional inertia and slack preventing them from intelligent and fast learning and strategic action.

It will be one of the major challenges for the European research system to build up efficient intelligence and reflexivity structures in order to avoid a reflexive collapse in a hypertrophic European bubble. And if an effective system of European discourse and reflexivity would materialise in the overall integration objective, i.e. an effective coordination of national policies and an improved division of labour between European, national and regional policy-instruments is yet fully unclear. The absence of real coordinative efforts at concrete policy-level makes it obvious that discursive and conceptual integration is merely a first step in that direction, and it is still much contested.

Where this all leads to, is still far from clear. We do not even have an appropriate system of analysis and intelligence to monitor these changes, to understand the relationships of different dynamics and put the picture together. Analysts still have to understand and digest such changes, adapt their research heuristics, and to adopt a more holistic view.

\section{Notes}

1) The paper is based on a presentation given at the First PRIME Network of Excellence Annual Conference "The Future of Research in Europe - a Knowledge Base for Policy and Management”, Manchester Business School, January $7^{\text {th }}-8^{\text {th }} 2005$.

2) The only integrative development at the institutional level in research policy within the EU had been the change of the voting mechanism for the Framework programme which since the Amsterdam Treaty is decided with majority vote.

3) Human resources, public and private investment in R\&D, impact of R\&D on competitiveness and employment, S\&T productivity; promotion of $\mathrm{R} \& \mathrm{D}$ culture and public understanding of science.

4) The trend chart activities include, besides the statistical data (scoreboard) comparative analyses of national policy portfolios in innovation policy, a database for policy measures and -actors, country reports, benchmarking reports and an intelligence service (see http://www.cordis.lu/tendchart).

5) Here the benchmarking of indicators of the innovation system and innovation behaviour is dealt with. Cf. European Commission: Commission Staff Working Paper: 2003 European Innovation Scoreboard; SEC (2003), Brussels, 10.11.2003 and http://www.cordis.lu/scoreboard/

6) This is the impression gained at various European conferences and informal exchanges with policy-makers.

7) Research Europe, 2 December 2004, p. 6.

\section{References}

Borras, S., 2004: System of innovation theory and the European Union. In: Science and Public Policy, vol. 31, no. 6, pp. 425-433

Borras, S.; Jacobsson, K., 2004: The open method of co-ordination and new governance patterns in the EU. Journal of European Public Policy, 11:2, April 2004, pp. 185-208

CREST, 2004: CREST report on the application of the Open Method of Coordination in favour of the Barcelona Research Investment Objective; October $1^{\text {st }}$ 2004, Brussels (Council Doc CREST 1206/04).

Edler, J., 2004: International Research Strategies of Multinational Corporations. A German Perspective. In: Technological Forecasting and Social Change 71 (2004), Nr. 6, pp. 599-621

Edler, J.; Havas A., 2004: Einbinden um aufzuholen. Die Erweiterung in der Forschungs- \& Technologiepolitik. In: OSTEUROPA 5-6 (54), pp. 413-429

Edquist, C., 2004: Systems of innovation: a critical review of the state of the art. In: Nelson, R. (ed.): Handbook of Innovation. Oxford: Oxford University Press 
Eurohorcs, 2004: EUROHORCS key principles for the foundation of a European Research Council (mimeo)

European Commission, 2000a: Towards a European Research Area, Communication from the Commission to the Council, the European Parliament, the Economic and Social Committee and the Committee of the Regions, Brussels, 18 January 2000, COM (2000) 6

European Commission, 2004a: ERA-Net: Frequently Asked Questions, Draft June 12004

European Commission, 2004b: Coordination of National Research Programmes. Background Document; 10/11/ 2004

European Commission, 2004c: Europe and basic research, Communication from the Commission, January 14, 2004

Frei, D., 1985: Integrationsprozesse. Theoretische Erkenntnisse und praktische Folgerungen. In: Weidenfeld, W. (ed.), Die Identität Europas. München, Wien: Verlag?, pp. 113-131.

Frietsch, R., 2004: Entwicklung der internationalen Wissenschaftskooperationen. Analysen im Rahmen der jährlichen Berichterstattung 'Zur Technologischen Leistungsfähigkeit Deutschlands', Karlsruhe (Studien zum deutschen Innovationssystem Nr. 11-2004)

Guzzetti, L., 1995: A Brief History of European Research Policy. Brussels, Luxembourg: Office for Official Publications of the European Communities

Haas, E.B., 1958: The Uniting of Europe. Political, Social and Economic Forces 1950-1957. Stanford: Stanford University Press

Haas, E.B., 1968: The Uniting of Europe. Political, Social and Economic Forces 1950-1957. $2^{\text {nd }}$ edition with a new preface. Stanford: Stanford University Press.

Hartwig, I.; Meyer, C.O., 2002: Towards Deliberative Network Governance? Theorising SocioEconomic Policy Coordination in the European Union; http://www.govecor.org

Lindberg, L., 1963: The Political Dynamics of European Economic Integration. Stanford: Stanford University Press

Lindberg L.; Scheingold S.A., (1970): The European Would-Be Polity: Patterns of Change in the European Community. Eaglewood Cliffs, NJ: Prentice Hall

Hurwitz, L. (ed.), 1980: Contemporary Perspectives on European Integration. Attitudes, non-Governmental Behaviour, and Collective Decision Making. London: Aldwych Press

Kuhlmann, S., 2001: Governance of Innovation Policy in Europe - Three Scenarios. In: Research Policy, vol. 30, issue 6/2001, pp. 953-976
Kuhlmann, S.; Edler, J., 2003: Changing Governance in European Research and Technology Policy. In: Edler, J.; Kuhlmann, S.; Behrens, M. (eds.): Changing Governance of Research and Technology Policy - the European Research Area. Cheltenham: E. Elgar, pp. 3-32

Marimon, R. et al., 2004: Evaluation of the effectiveness of the New Instruments of Framework Programme VI, Report of a High-level Expert Panel chaired by Professor Ramon Marimon, Brussels: European Commission

Mayor, F. et al., 2003: The European Research Council. A Cornerstone in the European Research Area. Report from an expert group. Copenhagen: Ministry of Science, Technology and Innovation

Presidency Conclusion, 2000: Lisbon European Council, March 23/24

Rifkin, J., 2004: The European Dream. Cambridge, UK: Polity

Stein, J.A., 2004: Is there a European knowledge system? In: Science and Public Policy, vol. 31, no. 6, pp. 435-447

Stone Sweet; A.; Sandholtz, W., 1997: European Integration and Supranational Governance. In: Journal of European public Policy 4 (3)

Wallace, W., 1990: Introduction: The dynamics of European Integration. In: Wallace, W. (ed.): The dynamics of European Integration. London: Pinter

\section{Contact}

\section{Dr. Jakob Edler}

Fraunhofer Institute for Systems and Innovation Research (ISI)

Breslauer Straße 48, 76139 Karlsruhe

Tel.: +49 (0) 721 / 6809 - 129

E-Mail: j.edler@isi.fraunhofer.de

Internet: http://www.isi.fhg.de/ti/index.htm

\section{Prof. Dr. Stefan Kuhlmann}

Fraunhofer Institute for Systems and Innovation Research (ISI)

Breslauer Strasse 48, 76139 Karlsruhe

Tel.: +49 (0) 721 / 6809 - 170

E-Mail: s.kuhlmann@isi.fraunhofer.de Internet: http://www.isi.fhg.de

Also: Utrecht University

Copernicus Institute

Innovation Studies Group

Heidelberglaan 2

PO Box 80115, NL-3508 TC Utrecht

The Netherlands

Tel: +31 - 30 - 253 - 1625

Internet: http://www.nwi.uu.nl 